\title{
COPING STRATEGIES ADOPTED BY IRAYA-MANGYAN HOUSEHOLDS DURING FOOD INSECURITY IN ABRA, OCCIDENTAL MINDORO, PHILIPPINES
}

\author{
Mary Yole Apple Declaro-Ruedas
}

Occidental Mindoro State College, San Jose, Occidental Mindoro, Philippines.

E-mail: tsinelas_yole@yahoo.com
Citation: Declaro-Ruedas, M.Y.A. 2019. Coping Strategies Adopted by Iraya-Mangyan Households During Food Insecurity in Abra, Occidental Mindoro, Philippines. J. Asian Rur. Stud. 3(1): $85-92$

\begin{abstract}
The study was conducted to determine the food security status of the Iraya Mangyans' and their coping mechanisms employed. The quantitative research design was employed in the study. The modified Radimer/Cornell Hunger and Food Insecurity instrument and Coping Strategy Index (CSI) were used to determine the food security status and their coping mechanism. Result shows the Irayas were middle aged, have medium household size, with low level of basic education, and with an average monthly income slightly "above" the poverty threshold in the province. The Irayas experienced "food insecure without hunger" in which household food supply is adequate but there is an adjustment to household food management, including reduced quality of food and increased unusual coping patterns. The high cost of food items and low agricultural production were the "highly serious problem" on food security. Dietary change, which includes relying on less preferred and less expensive foods and consuming less variety of foods, is the most employed coping mechanism. Household monthly income and years spent in formal school are significantly related to the coping mechanisms employed during food insecurity. However, household size and age have no significant relationship.
\end{abstract}

Keywords: Coping Strategies; Household; Philippines

\section{Introduction}

The United Nations defines the Right to Food as "the right to have regular, permanent and unrestricted access, either directly or by means of financial purchases, to quantitatively and qualitatively adequate and sufficient food corresponding to the cultural traditions of the people to which the consumer belongs, and which ensure a physical and mental, individual and collective, fulfilling and dignified life free of fear." The right to food has four dimensions: availability, accessibility (economic and physical), adequacy and food safety.

A related concept to this is food security, which was defined at the 1996 World Food Summit as existing "when all people at all times have access to sufficient, safe, nutritious food to maintain a healthy and active life". Commonly, the concept of food security is defined as including both physical and economic access to food that meets people's dietary needs as well as their food preferences. According to the FAO (2014), 
food security depends not only on the availability and access to sufficient food, but also on political stability and the absence of violence or terrorism, which may explain why conflict-areas (such as Mindanao) are 'more vulnerable' to hunger. The 1996 World Food Summit defined food security as the state "when all people, at all times, have physical and economic access to sufficient, safe, and nutritious food that meets their dietary needs and food preferences for an active and healthy life."

The Food and Nutrition Research Institute of the Department of Science and Technology (FNRI-DOST) calls hunger a severe form of food insecurity. Prolonged hunger may lead to malnutrition, illness, mental and physical growth retardation, among many other complications.

In 2014, the Philippines' Global Hunger Index (GHI) was 13.1. This index is based on three indicators: undernourishment, child underweight and child mortality. It uses a scale of 0 (no hunger) to 100 (hunger). The ideal score is less than 5, which indicates low hunger. The country is therefore ranked 29th in the world, with its situation categorized as a "serious problem" (IFPRI, 2014). More than a quarter of Filipino adults $(36 \%)$ claimed to be food insecure, while $23 \%$ of Filipino children (National Nutrition Survey, 2011).

The regions that are the most affected by hunger and food insecurity are rural. In Occidental Mindoro, Mangyan's are an ethnically marginalized people consist of six tribes, namely: Hanunuo, Buhid, Ratagnon, Tau-Buid, Alangan and Iraya. They live below the poverty threshold of the province due to seasonal agricultural production and are generally lacking in basic educational, nutritional, and healthcare support. Their livelihood is dependent on slash-and-burn or "kaingin" farming, which has essentially remained at subsistence level. The Mangyans experience almost similar difficulty in securing food at the household level. However, due to the topographic and cultural variation, status of food insecurity and coping mechanism employed may vary across tribes and areas.

The Buhids experienced "food insecurity with moderate hunger" in which adults in the households with and without children have experienced reductions in food intake. They employed "rationing change" as a coping mechanism, which includes limiting the amount of food given to each household member at mealtimes and reducing the number of meals eaten in a day [2].

Likewise, Ratagnons experienced "food insecurity without hunger" in which household food supply is adequate but there is an adjustment to household food management, including reduced quality of food and increased unusual coping patterns. They employed "dietary change" as a coping mechanism, which includes relying on less preferred and less expensive foods and consuming less food variety ${ }^{[3]}$.

While, Tau-builds experienced "food insecurity with severe hunger" in which the adults in households with and without children have repeatedly experienced more extensive reductions in food intake. The low level of income at household level and high cost of food items were the "highly serious problem" on food insecurity. They "increase short-term household food availability" as a coping mechanism, which includes borrowing of food from a friend or relative, purchasing of food on credit, reducing health or education expenditure to buy food, gathering indigenous food, and consuming seed stock stored for next season ${ }^{[4]}$. Thus, this follow up study was 
conducted to determine the household food security of the Iraya households in Occidental Mindoro.

Base on the above background this paper aims to define the socio- economic characteristics of Iraya households; describe the food security status and problems of food insecurity of the Iraya households; determine the household coping strategy employed during food shortage, and analyze the relationship between the socioeconomic characteristics of the households and their coping strategies.

\section{Methodology}

The study used descriptive research design. In-depth interview, focus group discussion, and 'food diary' were the methods used in the collection of data. Sixty Iraya households served as the respondents of this study ( $72 \%$ of the 85 households) from Abra, Occidental Mindoro.

To comply with research ethics protocol, the researchers obtained informed consent from the gatekeepers of the community such as the National Commission on Indigenous Peoples, LGU-Barangay, Council of Elders and other religious organization.

The mothers in each household served as the respondents. The mother-respondents were chosen based on the following criteria: 1) those who had both a pre-elementary and grade school child; and 2) those who had resided in the area for at least five years.

The Radimer/Cornell Hunger and Food Insecurity instrument was modified and utilized according to the cultural needs of the community. Further, only the items in the Coping Strategy Index (CSI) that were applicable to rural and food-producing households were used.

Descriptive statistics was used to describe the respondents' attributes and the coping mechanisms employed. While, the Pearson's Moment correlation was used to test the relationship among the variables.

\section{Results and Discussion}

\subsection{Iraya Mangyans of Abra, Occidental Mindoro}

According to the Mangyan Heritage Center (nd), the Iraya Mangyans live in the municipalities of Puerto Galera, San Teodoro and Baco in Oriental Mindoro but most are in Occidental Mindoro, particularly in the municipalities of Abra de Ilog, Paluan, Mamburao and Santa Cruz. During ancient times, the Iraya traditional attire was made of dry tree bark, pounded to make it flat and soft. The women usually wore a blouse and a skirt and the men wore g-strings made of cloth. Today, however, the Iraya are dressed just like the lowland people. Ready-to-wear clothes are easier to find than their traditional costume (Uyan, 2002 as cited in Mangyan Heritage Center, nd). The Irayas are also skilled in nito-weaving. Handicrafts such as jars, trays, plates and cups of different sizes and design are being marketed to the lowlanders.

Results show they have a mean age of 46.00 years old. This means that they were still in the middle age and can still perform the work requirements in doing reproductive and productive activities. They have a big household size with 7.20 members ranging from 3-10 members. 
Majority has attended formal schooling, with basic education (Grade 6). They can read and write their names and perform basic mathematical operations. It is noteworthy that today, they send their children to school but the latter could not continue their schooling because of lack of finances and distance to a secondary school.

The annual per capita poverty threshold for the Occidental Mindoro, Philippines in 2009 stood at P16,169.00 ${ }^{[7]}$. During the first semester of 2015, a family of five needed at least PhP 6,365 on the average every month to meet the family's basic food needs and at least PhP 9,140 on the average every month to meet both basic food and non-food needs. These amounts represent the monthly food threshold and monthly poverty threshold, respectively ${ }^{[1]}$. They subsist on rice, banana, sweet potato, and other root crops.

Thus, the Irayas lives "below" the poverty line. Their average monthly income per household with 7.20 members is Php 1122.23 and almost half of the average income is allocated to food, which ranges from Php 350.00-1200.00. This could be due to 'tagkiriwi' or the difficult times experienced by the Irayas during the months of July and September. At this time, activities in the kaingin and lowland farms are already finish. Thus, they do not have a daily source of income.

Table 1. Socio-economic characteristics of the Iraya Households.

\begin{tabular}{lcc}
\hline \multicolumn{1}{c}{ Socio-economic Variables } & Mean & Range \\
\hline Age & 46.00 years old & $22-80$ years old \\
Formal years spent in school & 6.00 years & $0-12$ years \\
Household size & 7.20 members & $3-10$ members \\
Household Monthly Income & Php 1122.23 & Php 500.00-5000.00 \\
Monthly Income allotted for food & Php 850.25 & Php 350.00-1200.00 \\
\hline
\end{tabular}

\subsection{Status of household food security of the Iraya Mangyan}

Household food security pertains to the ability of a household to assure all its members sustained access to sufficient quantity and quality of food to have a healthy life. The status of food security was categorized based on the following: a. food secure - household shows no or minimal evidence of food insecurity. it means that they have enough food to eat; $b$. food insecure without hunger - household food supply is adequate but there is an adjustments to household food management, including reduced quality of food and increased unusual coping patterns; c. food insecure with moderate hunger - food-insecure households with children shows that there is not enough of foods to eat. thus, there is a reductions of food for adults but not for children; and d. food insecure with severe hunger - at this level, adults in households with and without children have repeatedly experienced more extensive reductions in food intake.

Results revealed that majority $(63.33 \%)$ of the Iraya households are 'food insecure without hunger. It reveals that the household's food supply is adequate but there is an adjustment to household food management, including reduced quality of food and increased unusual coping patterns. 
Table 3. Status of food security.

\begin{tabular}{lcc}
\hline \multicolumn{1}{c}{ Status of food security } & Frequency $(\mathbf{n}=\mathbf{6 1})$ & Percentage (\%) \\
\hline Food secure & 5 & 8.33 \\
Food insecure without hunger & 38 & 63.33 \\
Food insecure with moderate hunger & 12 & 20.00 \\
food insecure with severe hunger & $\underline{5}$ & $\underline{8.33}$ \\
& 60 & 100 \\
\hline
\end{tabular}

Table 4. Food insecurity problems.

\begin{tabular}{|c|c|c|}
\hline Problem of household food security & Mean & Interpretation \\
\hline Low level of income at household level & 4.56 & Highly serious \\
\hline Accessibility to market & 3.21 & Moderately serious \\
\hline High cost of food items & 3.42 & Moderately serious \\
\hline Insufficiency of food items & 4.23 & Serious \\
\hline Presence of the food cash transfer program & 2.34 & Less serious \\
\hline Low agricultural production & 4.56 & Highly serious \\
\hline Natural disasters (flood, typhoons, soil erosion, etc) & 4.24 & Serious \\
\hline Overall mean & 3.79 & Serious \\
\hline
\end{tabular}

Legend: 0.50-1.50- Not serious; 1.51-2.50- Less serious; 2.51-3.50- Moderately serious; 3.51-4.50-Serious; 4.515.00-Highly serious

\subsection{Problem of food insecurity}

Table 4 shows the group identification of problem of food insecurity encountered by the Iraya households. The low level of income at household level (mean=4.56) was rated as "highly serious problem," which shows that the price of most food products had increased and was affecting the ability of poor households to purchase adequate food. This was more so as the majority of them relied on one, often unreliable, income source such as farming.

Since, farming was the main income source for most of them who are kaingin farmers, where they usually keep only $10-15 \%$ of the harvest and the rest of the produce were sold in the town market. The situation is compounded by low agricultural production (mean=4.56) due to high cost of fertilizers, limited access to irrigation and overall poor agricultural practices that result in productivity and low yields ${ }^{[9]}$.

In a subsistence agrarian economy survival is rooted in a complex combination of production activities and social exchange. A poor harvest or a crop failure would not only mean decrease in food intake, but also it may imply the sale of valuables or livestock at a depressed price (at the longer rate) which has the knock on effect on reducing the ability of achieving adequate subsistence in the following year. A chronic food security in a subsistence economy may become a famine in circumstances when production drops by even a minor extent: the meager household exchange entitlement is exhausted; and traditional welfare mechanisms ceased to function ${ }^{[8]}$.

A food system close enough to the "survival minimum" in subsistence agrarian economies has a low threshold for disaster. Scott (1986) noted that the significance of this "disaster level" obviously depend on the structure of 
alternative employment and other economic opportunities. This is due to the fact that many people in subsistence economies are endowed with a limited range of entitlements and so production failure may be enough to induce food shortage or even famine ${ }^{[8]}$.

\subsection{Food insecurity coping strategies}

Coping strategies are invoked following a decline in "normal" sources of food and these are regarded as involuntary responses to disaster or unanticipated failure in major sources of survival [5].Adopting any of the coping strategies described in Table 5 has implications for the household and its members. The overall mean of 3.80 shows that the different coping strategies were "often practice."

When there is not enough money to spend for food, the respondents "always" Rely on less preferred and less expensive foods (mean=4.78) and consume less variety of food (mean=4.68). These strategies are considered as a "dietary change." They also practice betel nut chewing to satisfy hunger.

Borrow food from a friend or relative is "often" employed (mean=4.41), which portrays the close knitted characteristics of Filipino families. Further, they also "often" limits portion size at mealtimes (mean=3.52) and skip entire days without eating (mean=3.57). However, the decrease in the number of daily meals or a decline in the quality of food consumed can be harmful to the health of household members especially to the long-term well-being of children ${ }^{[1]}$.

The "never" to send children to eat with neighbors (1.27) and let some household members to beg (1.27) in the municipal town or nearby municipalities.

Table 5. Food insecurity coping strategies.

\begin{tabular}{|c|c|c|}
\hline Coping mechanisms & Mean & Interpretation \\
\hline \multicolumn{3}{|l|}{ Dietary change } \\
\hline Rely on less preferred and less expensive foods & 4.78 & Always \\
\hline Consume less variety of food & 4.68 & Always \\
\hline \multicolumn{3}{|l|}{ Increase short-term household food availability } \\
\hline Borrow food from a friend or relative & 4.41 & Often \\
\hline Purchase food on credit & 4.43 & Often \\
\hline Reduce health or education expenditure to buy food & 4.21 & Often \\
\hline Gather indigenous food, and hunt wild animals & 4.27 & Often \\
\hline Consume seed stock held for next season & 4.67 & Always \\
\hline \multicolumn{3}{|l|}{ Decrease numbers of people } \\
\hline Send children to eat with neighbors & 1.27 & Never \\
\hline Send household members to beg & 1.27 & Never \\
\hline \multicolumn{3}{|l|}{ Rationing strategies } \\
\hline Limit portion size at mealtimes & 3.52 & Often \\
\hline Restrict consumption by adults in order for small children to eat & 4.21 & Often \\
\hline $\begin{array}{l}\text { Reduce number of meals eaten in a day/ skip a meal or two } \\
\text { during the day }\end{array}$ & 4.21 & Often \\
\hline Skip entire days without eating & 3.57 & Often \\
\hline Overall mean & 3.80 & Often \\
\hline
\end{tabular}

Legend: $0.50-1.50=$ never; $1.51-2.50=$ Sometimes, in about $30 \%$ of the chances when I could have; 2.51 $3.50=$ Seldom, in about $50 \%$ of the chances when I could have; $3.51-4.50=$ Often, in about $70 \%$ of the chances when I could have; $4.51-5.50=$ Always, in about $90 \%$ of the chances I could have 


\subsection{Relationships between the socio-economic characteristics and the coping mechanism employed}

The hypothesis was tested using Pearson Product Moment Correlation to determine the relationship between the selected socio economic characteristics and coping strategies of the respondents. The results of the findings revealed that the coping strategies of the respondents were influenced by years spent in formal education and household monthly income at 5\% level of significance.

Table 6. Relationship between the socio-demographic characteristics and coping strategies.

\begin{tabular}{lccl}
\hline \multicolumn{1}{c}{$\begin{array}{c}\text { Socio-demographic } \\
\text { characteristics }\end{array}$} & \multicolumn{2}{c}{ Coping Strategies } & \\
\cline { 2 - 3 } & Computed $\boldsymbol{r}$ & Critical $\boldsymbol{r}$ & Interpretation \\
\hline Age & 0.021 & 0.150 & Not Significant \\
Formal years spent in school & 0.163 & 0.150 & Significant \\
Household size & 0.148 & 0.150 & Not Significant \\
Household Monthly Income & 0.172 & 0.150 & Significant \\
\hline
\end{tabular}

\section{Conclusions}

Based on the pertinent findings, the following were the conclusions drawn from investigation:

1. The Irayas were middle aged, have medium household size, with low level of basic education, and with an average monthly income slightly "above" the poverty threshold in the province.

2. The Irayas experienced "food insecure without hunger" in which household food supply is adequate but there is an adjustment to household food management, including reduced quality of food and increased unusual coping patterns. The high cost of food items and low agricultural production were the "highly serious problem" on food security.

3. Dietary change, which includes relying on less preferred and less expensive foods and consuming less variety of foods is the most employed coping mechanism.

4. Household monthly income and years spent in formal school are significantly related to the coping mechanisms employed during food insecurity. However, household size and age have no significant relationship.

\section{Recommendation}

The study recommends conducting the same research in other IP communities and consolidating its findings to craft a holistic and integrated intervention on food security. 


\section{References}

Arimond, M. and Ruel, M., (2004). Dietary Diversity Is Associated with Child Nutritional Status: Evidence from 11 Demographic and Health Surveys in Journal of Nutrition, Vol. 134, 2004, pp 2579-2585.

Declaro-Ruedas, M. (January 2015). "Rationing Change as Coping Strategy Employed by Buhid Households against Food Insecurity.” JPAIR Multidisciplinary Research Vol. 19

Declaro-Ruedas, M. (May 2015). "Factors Contributing To Household Food Insecurity of The Ratagnon Mangyans In Occidental Mindoro." 1st International Conference on Interdisciplinary Studies for Cultural Heritage (ISCH) Book of Conference.

Declaro-Ruedas, M. (2017). Food Shortages And Crisis Copping Strategies Among The Tau-Buid Households In Occidental Mindoro, Philippines. A Paper presented during the STIRDC Conference on January 2017, at San Jose, Occidental Mindoro

Ellis, F., (2000). Rural Livelihoods and Diversity in Developing Countries. Oxford University Press.

Mangyan Heritage Center.(nd)., Tau-Buid. Retrieved March 15, 2016, from mangyanheriatage.com

Philippine Statistics Authority (PSA). (2015). Annual Per Capita Poverty Thresholds by Province, 2012 - 2013

Scott, R., (1986). Famine in Peasant Societies. Contributions in Economics and Economic History. Number 66, Green Wood Press. London.

World Food Programme (WFP). (2006). Comprehensive Food Security and Vulnerability Analysis (CFSVA). http://www.laofab.org/document/view/36. Accessed on 12 January 2016. 